\title{
Foundation for Building a Community Medical and Social Service Organization
}

\author{
M. Basheer Ahmed, MD \\ Founder and Chairman of Muslim Community Center for Human Services \\ Tarrant County, Texas
}

\begin{abstract}
The Muslim Community Center for Human Services (MCCHS) in Tarrant County, Texas, is a nonprofit, charitable organization providing medical and social services to underserved populations, especially immagrants and those who lack health insurance. Relying primarily upon volunteer staff and donations, the center has been able to add more and more medical and social services in its 13 years of operations. This center reflects the changing priorities of Muslims in the United States.
\end{abstract}

Key words: Public health, charitable organizations, domestic violence, charitable medical services.

$\boldsymbol{I}$ have periodically reported on the activities of the Muslim Community Center for Human Services (MCCHS). $0^{1-3}$ This article adds additional details of concern to practitioners who may consider either founding similar organizations or participating in existing charitable medical and social service providers.

Underserved Populations: The Uninsured and Immigrants

In this country, 47 million Americans do not have health insurance. ${ }^{4}$ Twenty-five percent of Texans are uninsured and are not eligible for public medical care. Ninety-seven thousand illegal immigrants reside in Tarrant County, which includes Fort Worth

Dr. Ahmed is in private practice psychiatry and is a former professor of psychiatry at Southwestern Medical School. Correspondence should be directed to

Dr. M. Basheer Ahmed 10 Homeplace Court Arlington, Texas 76016 Email:mbahmed03@hotmail.com and Arlington, and do not have insurance coverage. ${ }^{5}$ Unfortunately, people without health insurance tend to be sicker and die at a relatively younger age. Due to lack of insurance, they generally delay physician visits and do not receive medical care for common medical problems such as hypertension and diabetes until they develop full-blown symptoms or complications. Another sad fact is that many hospitals and physicians agree to bill and receive negotiated discounted prices for their services from private and governmental third party payers but bill the full amount to individuals who do not have insurance coverage. Many uninsured individuals in an emergency have to use their life's savings for surgery or treatment in intensive care units.

The number of uninsured Americans has been rising inexorably over the past 8 years due to a variety of reasons. 6 Families who have good insurance may lose it if the bread-winner becomes unemployed. Individuals who are earning more than the poverty level are not eligible to receive care at public hospitals and clinics. Visitors to the United States and illegal residents are not eligible for care at the public hospitals or clinics.

Regardless of age, legal status, or insurance cov- 
erage, immigrants receive much less health care than native-born Americans. Based on data collected from 1996-1998, a high percentage of immigrants are uninsured, and they use 55\% fewer services than nonimmigrants. Financial, cultural, and language difficulties make it hard for immigrants to access care. Immigrant children had $74 \%$ lower per capita health care expenditures than U.S.-born children. ${ }^{7}$

Immigrants also have difficulty in following medical recommendations and often are noncompliant. Many immigrants do not understand the significance of elevated blood pressure or high cholesterol as long as they are not experiencing any obvious symptoms. Compared to nonimmigrants, immigrants pay little attention to preventive measures such as diet and exercise. Many elderly immigrants who have not worked in the United States are not eligible for Medicare coverage.

\section{Establishing MCCHS for Providing Medical and Social Services}

It was in the late 1990s that Muslims started paying attention to social issues. To deal effectively with the social problems was a difficult task. Few acknowledged the existence of these problems. The denial and stigma attached to these problems also created a major hindrance. There was a general fear that social issues would not elicit support from other Muslims. However, the center's organization was established in September 1995.

A Board of directors was selected to provide the organizational leadership. Its members were selected based on their expertise and commitment. All board members were responsible for fund development and financial support as necessary. Fund raising dinners, soliciting local physicians and business leaders by mail for donations, requesting local Muslim organizations to underwrite special projects such as health fairs and seeking grants for specific programs were some of the approaches used to raise funds. Although it has won some grants, MCCHS's major source of funding is donations from individuals.

\section{Charitable Medical Services - Al-Shifa Clinic}

In view of the health care issues discussed above, the Al-Shifa Clinic was opened in October 1998. The clinic is a private not-for-profit agency providing culturally appropriate primary care to medically underserved populations, indigent patients, and visitors from overseas without insurance coverage. The weekly clinic provides services for general medical problems such as diabetes, hypertension, high cholesterol, and minor infections. If these problems are not treated at an early stage, they may lead to more serious problems such as heart disease, stroke, or kidney failure, which can result in more serious consequences for the patients and their families. All surgical and complicated medical cases are referred to public hospitals in this area. Fifteen area physicians donate their time to the Saturday rotations. In addition to free consultation, generic or free medications (donated samples) are also prescribed or dispensed. In 2002, discounted rates were negotiated for lab work, and now laboratory services are also provided. Most of the physicians at the MCCHS clinic are internists and primary care physicians. Some area specialists see patients for free consultations in their own offices when referred by Al-Shifa. Students from local medical schools also help at the clinic, getting credit for their work. Foreign medical graduates applying for residency programs also attend the clinic as "observers" and work under the supervision of attending physicians.

Initially, the clinic was open every Saturday for 4 hours. Many Muslim women prefer to see female physicians due to religious and cultural modesty. Therefore, beginning in 2007, the clinic opened on Sundays for women and children only. Female physicians and a pediatrician volunteer their time at the women's clinic. In July 2008, an eye clinic opened once a month for minor ophthalmologic problems and offered glasses for visual correction. The community center is also planning to open a dental clinic in mid-2009.

\section{Staffing the Clinic}

Prior to establishing the clinic, several area physicians were contacted to discuss the feasibility of opening the charitable clinic. Fifty physicians expressed interest in volunteering. However, only 15 made the commitment to come to the clinic for 3-4 hours once in 2 months. The major question physicians had related to malpractice insurance. It was recommended that physicians who are in private practice notify their insurance carrier about their work at the clinic and get appropriate malpractice insurance coverage. Physicians working at the 
United States Veterans Administration or other governmental institutions cannot get the coverage through their insurance company. The Texas Medical Association provided extensive information on good Samaritan laws governing charitable medical clinics and the protection they offer to physicians. Texas medical liability insurance provides coverage to retired physicians providing volunteer services at charitable clinics for the nominal charge of $\$ 250$ per year. The federal government also offers malpractice coverage with no cost to physicians who provide free services at charitable clinics.

Recruiting and keeping physicians interested in the charitable clinic is challenging. Since the inception of the clinic, MCCHS has lost a few physicians to family responsibilities and other commitments. The center constantly recruits replacement physicians.

\section{Operations}

A part-time office manager was hired to make appointments, maintain medical records, supervise nonphysician volunteers, and arrange the lab work. The medical record contains the physician's initial work up, progress notes, lab work and a list of prescribed medications. A pharmacist comes to the clinic periodically and sets up policies for recording the use of sample medications and disposal of expired medications. A physician dispenses the medication from the pharmacy, which is a locked room where the medications are stored.

The clinic only accepts patients who have no insurance and are unable to pay the physician's fee in private practice. It is difficult to do a financial assessment on every patient who comes to the clinic due to lack of staff and the high logistical costs. However, MCCHS believes that $90 \%$ of the patients meet its criteria for free medical care.

Al-Shifa clinic served 1200 patients in 2006, 1500 in 2007, and 1800 in 2008. Ninety-five percent of the patients at the clinic are adults. The clinic sees a small number of children whenever the pediatrician is able to come to the clinic. Seventy percent of the patients at the clinic are women, and 30\% are men. The most common problems treated at the clinic are diabetes (30\%), heart disease including hypertension and high cholesterol (40\%), infections and other minor ailments (15\%.), and depression, anxiety and other psychiatric problems (15\%). Al-Shifa refers patients with acute medical problems such as chest pain, acute infections, surgical problems, and chronic medical conditions to public hospitals.

Most of the patients at the clinic have no other source of receiving treatment. The clinic does reduce the burden of public hospitals and emergency rooms. Patients also feel more comfortable with physicians who understand their culture, language, and religious beliefs.

\section{Health Fairs}

The major purpose of health fairs is to detect common health problems such as hypertension, diabetes, and high cholesterol. These diseases may lead to serious health problems if not detected at an early stage. On an average, 10 to 15 individuals are identified as in need of medical care. Such patients are referred to physicians in the community, public hospitals, or Al-Shifa Clinic.

These health fairs are held in different locations in Dallas/Fort Worth metropolitan area. Several health fairs have been held mainly in the mosques and community centers. In 2003, MCCHS organized a health fair jointly sponsored by area churches, and $25 \%$ of the participants were non-Muslim. It was the first interfaith event of its kind in this area. During the health fairs, MCCHS offers blood pressure checking, medical consultation, pediatric examination, and dental and eye examination, as well as tests for cholesterol and blood glucose levels. Lectures on different topics including heart disease, diabetes, and cancer are given. Many individuals make use of the opportunity to discuss and get professional advice on physical or emotional issues. For the last two years, MCCHS has been holding health fairs twice a year. One is in South Dallas in conjunction with the Humanitarian Day initiative (humanitarianday.com). It primarily serves indigent African-American residents of the area irrespective of religious affiliation. The other health fair is usually held in one of the Islamic centers, and all the area residents are encouraged to take advantage of the free health screenings. More recently, MCCHS also participated in the health fair organized by Dallas County Department of Health as a part of the commemoration of Kwanza.

In addition to physicians, medical and nursing students also help in the health fair. Several agencies such as the American Heart Association, American Cancer Society, the Public Health Department, Red 
Cross, and other agencies provide educational material. During the health fairs participants also may donate blood, and women may register for mammograms.

\section{Breast Cancer Education Program}

MCCHS received a grant to provide education to the immigrant community on breast self-examination and the importance of mammograms for early detection of cancer. Many immigrants, especially Muslims from the Middle East, South Asia, and Africa, lack knowledge and understanding about the importance of early detection. The small grant from the Susan G. Komen foundation enabled the organization to recruit a community outreach worker to arrange educational seminars in Urdu and Arabic. In addition to a physician, a breast cancer survivor is invited to speak at these seminars. Al-Shifa also provides free mammograms to indigent residents by making arrangements with the local mammogram mobile unit. In 2006, 33 free mammograms were provided, and in 2007, 48 mammograms were arranged for indigent residents.

\section{Mental Health and Counseling Services}

There are many charitable clinics in the country that offer only medical services. However, from its inception, MCCHS made a decision to provide medical, psychiatric, and social services under one umbrella. It offers treatment and counseling to patients with emotional problems. A volunteer psychiatrist and a staff social worker assess, diagnose, and treat emotional problems. Ten to fifteen patients a month come to the clinic with emotional, marital and other problems. These patients are treated with medication as well as with counseling; however, the clinic does not accept patients with serious mental problems such as schizophrenia, severe personality disorders, and patients with active suicidal thoughts. These patients are referred to public mental health clinics.

\section{Marital Counseling}

All religions promote the concept of healthy marriages. Allah dule says:

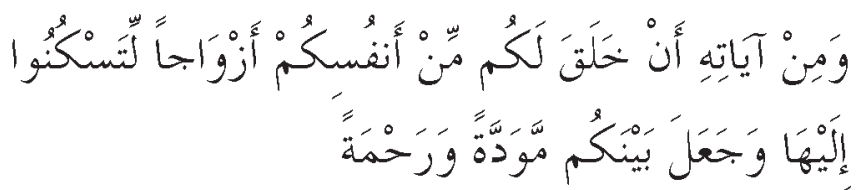

Among His signs is that He created for you mates from among your self and that you may dwell in tranquility with them and $\mathrm{He}$ has put love and mercy in your hearts. ${ }^{8}$

A satisfactory marriage has a positive effect on physical, emotional, and spiritual health. On the other hand, the unsatisfactory or unhappy marriage will have a negative effect on health, finances, and children. Of course, many unhappy marriages end in separation or divorce, also having a negative influence on adults and children. The clinic offers premarital, marriage, and divorce counseling. The major goal of premarital counseling is to prepare young people who are planning to get married to face the realities of married life, giving them an opportunity to openly express their likes and dislikes, preferences and priorities. The major goal of marriage counseling is to reduce the incidence of divorce and the breaking up of the family unit. If divorce becomes inevitable, we recommend mediation to avoid costly legal expenses and counseling with children to reduce the trauma.

\section{Domestic Violence Program - Roshni}

The recent arrest of a prominent Muslim businessman on the charge of murdering his wife in February 2009 became a wake-up call for the Muslim community, the majority of which does not believe that domestic violence exists in the Muslim community. The victim had recently filed for divorce after previous incidents of domestic violence.

In the United States, there is a staggering number of assaults against women by family members and other intimates resulting in death, injury, disability, and mental trauma.9,10 Children are also victims within an abusive household.

Some people erroneously assume that because the United States and other industrialized societies report such high numbers of abuse incidents, domestic violence must be a "Western" problem. In many third world countries, Muslim countries included, there are no services or support for victims of domestic violence and no means to collect such data. Thus, the incidence reported will be low. As part of her Ph.D. dissertation, Najma M. Adam, Ph.D, conducted a study on domestic violence against women within South Asian communities in the United States. Nearly $73 \%$ of the 61 women she interviewed 
had experienced psychological abuse, $48 \%$ physical abuse, 54\% sexual abuse, and nearly 39\% incurred injuries due to the abuse. Many of the victims were quite reluctant to share information with her. ${ }^{11}$

It is true that many Muslim women, who are the victims of abusive behavior, do not discuss their issues with families and friends and seldom report to the authorities unless it becomes out of control. There are multiple factors for not reporting the abusive and violent behavior of the spouse: Lack of support system, religious and cultural inhibitions, poor self confidence, and accepting the abuse as a normal behavior. The abusive men attempt to place their partners in a submissive role. The abusive behavior is a learned behavior, which is acquired through life experiences in one's own family of origin and through the observation of society at large. The abusers believe that they have the right to control others' behavior.

Physicians must be knowledgeable about the dynamics of domestic violence and must screen all female patients for the signs of domestic violence. Physicians need to ask direct questions, especially to patients who have an unexplained injury or multiple vague symptoms. They also must be aware of resources to which they can refer the patients..$^{12}$

Domestic violence is a crime; it is not a private family matter. If community leaders and health professionals are not aware and involved, women will be victims for many years.

The domestic violence program at MCCHS, Roshni, was established 5 years ago. Initially, we developed a helpline and started providing outpatient counseling and referral to the appropriate agencies as needed. We also developed a relationship with other service providers, especially the shelters in the Dallas/Fort Worth area. We have expanded the program during the last 2 years and offer educational programs in various Islamic centers in the area at least four to six times a year. Here they share information about recognizing the early signs of domestic violence and provide available resources. The first full-time social worker was hired in 2006, and we trained six volunteers to receive calls. In 2008, we hired another full-time social worker to provide counseling and support services. Now, we receive 6-8 calls a month from victims of domestic violence, and we carry a case load of 23-25 cases. MCCHS has sent a one-page document to all the
Muslim physicians about recognizing symptoms of domestic violence and the available community resources. I have also published a paper on this subject in the Tarrant County Medical Society Journal. ${ }^{13}$

\section{Abused Children and Child Protective Agencies}

Although there is denial in the community, MCCHS receives calls from families where the children are taken by Child Protective Services for abuse and negligence. We have held seminars for parents informing them about the local laws regarding child abuse and neglect, with the goal of deterring them from behaviors which, however unacceptable, do not subject them to arrest, punishment and restriction of parental rights in their home countries. Many parents do not realize that law enforcement and social services in the United States will intervene in this manner in response to reports of beating and other forms of abuse and neglect. Some uninformed parents, rather than cooperate with police and social services and commit to changing their behavior, complicate and jeopardize resolution of the problem through blaming the government. The community center works closely with child protective agencies, and on numerous occasions, children were returned to parents through the involvement of MCCHS and parents' commitment that they would receive counseling from MCCHS. In serious situations, when the child cannot be returned to the parents, MCCHS attempts to locate Muslim foster parents for placement of the children. Unfortunately, there is a lack of foster parents to take care of Muslim children. ${ }^{14}$ The community center works very closely with the child protective agency to train Muslim foster parents for emergency placement of children.

\section{Guidelines for Health Care Providers}

More than 150,000 Muslims live in the Dallas/Fort Worth area. Because physicians, nursing staff, and chaplains associated with hospitals, home health care agencies, hospices, and county departments of health may encounter Muslim patients. MCCHS has prepared a brochure to make them familiar with the religious and cultural sensitivities of Muslim patients, covering the subject of personal hygiene, prayers, diet, interaction with female patients, and Muslim views on illnesses and death. This brochure was circulated to every hospital and many other providers in the Dallas/Fort Worth met-

JIMA: Volume 41, 2009 - Page 74 
ropolitan area. The community center also conducted educational programs for various hospitals and health care agencies on this subject.

\section{Senior Citizen Program}

The Muslim community has a significant number of senior citizens for whom MCCHS is providing services. Special lunch programs for seniors were organized to give them opportunity to socialize and learn about health issues, government assistance programs such as Social Security, Medicare and Medicaid, and immigration problems.

\section{Services for Immigrants}

The arrival of a significant number of Muslim refugees from Somalia and Bosnia to the Dallas/Fort Worth region, especially since late 1996, obliged MCCHS to hold workshops on social services and immigration issues. The community center assisted in settling the Somali and Bosnian refugees by providing financial assistance for which a separate fundraising program was held. Clothes and household goods were collected and distributed. The MCCHS collaborated with government agencies working very closely with the Somalian Outreach Program. Somali and Bosnian patients also visit the MCCHS medical clinic. The clinic is now offering services to newly arriving refugees from Burma and Iraq.

\section{Outreach Program}

In 2003, MCCHS, along with local churches, started participating in feeding the hungry at a homeless shelter. Volunteers from MCCHS cook and serve one hot breakfast per month for 80-100 residents at the Arlington Life Shelter. During Ramadan, MCCHS also serves one dinner. Additionally, MCCHS collected and distributed clothes and school supplies for children living at the shelter with their parents.

\section{Education and Seminars}

The community center holds periodic educational seminars including parent/child issues (for example, "Parents Just Don't Understand"), marital conflicts and disharmonies, challenges women face in America, and a variety of health issues (stroke, diabetes, cancer, and heart disease), and mental health issues (depression). Special lectures for senior citizens focus on various health issues, breast cancer, prostate cancer, diabetes, and heart disease.

\section{International Health Visitors}

At the request of the U.S. State Department through the Cancer Society of Dallas, MCCHS hosted a brief program on November 6, 2007, for 17 physicians and health care professionals from Bahrain, Egypt, Israel, Jordan, Lebanon, Libya, Morocco, Oman, Saudi Arab, Syria, and Palestine. The board members and staff presented the MCCHS's breast cancer education programs. The major goal of MCCHS is to alert all adult women from the Middle East, Somalia, and South Asia to have early breast cancer screening by having periodic mammograms. Free mammograms are arranged for individuals who have no insurance or are unable to afford the payment for the mammogram.

Many Muslim organizations are involved with religious, educational, and political issues; however, very few organizations are involved in providing medical and social services. We have a responsibility to those who are in need of such services but cannot access them. We must make every effort to provide medical and social services to all deserving community members. We must accept that health care accessibility is a human right, and we need to do our best to make this happen by providing direct care to the needy and supporting legislation that makes health care accessible to everybody. It is time that Muslims take a leadership role in offering medical and social services, not only to the Muslim community but to the nation at large as well. We are Americans, and we have a responsibility to promote welfare in our nation. We need to train our youth to become the future leaders by carrying out the programs we are in process of developing.

\section{References}

1. Ahmed MB. Texan Muslims focus on social services. Islamic Horizons. May/June 1998:30-31.

2. Ahmed MB. Dallas-Fort Worth Muslim health fair. J Islam Med Assoc. 2000;32:128-30.

3. Ahmed MB. Southern care. Islamic Horizons. 2008;37(3):26-7.

4. Eckholm E. Hospitals try free basic care for uninsured. The New York Times. 2006 Oct 25. Available from http://www.nytimes.com/2006/10/25/health/ 25insure.html.

5. Allied Communities of Tarrant County, Texas. A 
matter of life: the Tarrant County Healthcare Initiative. Available from h t $\mathrm{t} \mathrm{p}:$ / / a l l i e d c o m m u n i ties.org/downloads/A_Matter_of_Life_2_7_07_web_ FINAL.pdf. [Updated 2007 Feb; Accessed 2009 May 24].

6. New York Times Editorial Staff. A sobering census report: bleak findings on health insurance. The New York Times. 2007 Aug 29. Available from http://www.nytimes.com/2007/08/29/opinion/29w ed2.html.

7. Mohanty SA, Woolhandler S, Himmelstein DU, et al. Health care expenditures of immigrants in the United States: a nationally representative analysis. Am J Public Health. 2005;95:1431-8.

8. The Glorious Qur'an Chapter 30, Verse 21.

9. Rennison CM. Intimate partner violence, 19932001. Bureau of Justice Statistics Crime Data Brief. 2003 Feb. Available from http://www.ojp.usdoj.gov/ bjs/pub/pdf/ipv01.pdf.

10. Greenfeld LA, Rand MR, Craven D, et al. Violence by intimates: analysis of data on crimes by current or former spouses, boyfriends, and girlfriends.1998 Mar. Available from http://www.ojp.usdoj.gov/bjs/ pub/pdf/vi.pdf. [Updated 1998 May 29; Accessed 2009 May 24].

11. Adam NM. Domestic violence against women within immigrant Indian and Pakistani communities in the United States. CrescentLife.com [web page]. Available from

http://www.crescentlife.com/psychissues/dv_us_i mmigrants.htm. [Accessed 2009 Apr 22].

12. Flitcraft AH, Hadley SM, Hendricks-Matthews MK, et al. Diagnostic and treatment guidelines on domestic violence. Chicago, Ill.: American Medical Association, 1992.

13. Ahmed MB. Domestic violence-responsibilities of physicians. Tarrant County Physician. 2008;80(5):911.

14. Ahmed MB. Muslim foster homes. Islamic Horizons.1998 May-June:31. 